\title{
Paweł Górski
}

Department of Pneumology and Allergy, Medical University of Lodz, Poland

\section{Are e-cigarettes good or bad?}

\author{
The author declare no finacial disclosure
}

The first generation of e-cigarettes appeared on the EU market in 2006 and soon after it was introduced in the United States. It seems to be very difficult to compare health effects of all of the three generations. Differences are related to the satisfaction of using the variety of flavouring agents and more acceptable devices.

E-cigarettes are manufactured mainly in China. There are high or even extremely high differences in product engineering, nicotine concentrations, and quality of other compounds used as carriers neccessary to produce vaporizing aerosols.

A frequently described dangerous issue is the possibility of modifying devices for using them to deliever marijuana or other drugs. Till now almost 2500 papers have presented variable data about individual health effects and the impact of e-smoking on public health.

It is commonly accepted that e-cigarettes are less harmful than tobacco smoking especially to the lungs and cardiovascular system. However, especially for cancerogenic agents, even small risks of adverse effects should be regarded as unacceptable. One should remember that for such agents there are no low limits of doses or concentrations in inhaled air. In fact concentrations of formaldehyde, an undoubtful cancerogenic agent, classified by IARC (International Agency for Research on Cancer) as the 1 group, in e-cigarettes vary between many products, in some of them exceeding concentration in tobacco cigarettes. Acrolein is also present in e-cigarettes in concentrations responssible for irritant and inflammmatory effects of airways. Exposure to propylene glycol and glycerin as ingredients of the liquid causes not only eye and airway irritation, but also affects the central nervous system, behaviour and the spleen.

For pneumologists and from toxicological point of view, it seems to be very important that the size of the particles distributed in aerosol from e-cigarettes is in the respirable range that leads to alveolar deposition. The liquid produces lung inflammation, pulmonary oxidative stress, diminishes levels of glutathione, thus changing the oxidation/antioxidation balance.

An unexpected result of the use of e-cigarettes is explosion and fire that was recently described [1].

A number of e-smokers has rapidly increased over recent years. In 2010, a total of 1.8\% of adult Americans used e-cigarettes but the rate rosed to $13 \%$ by 2013 [2]. Poland is a country of one of the highest number of e-cigarettes young users since $19 \%$ of people below 20, who never smoked tobacco and $57 \%$ of current smokers use e-cigarettes [3]. Although tobacco smokers are most likely to be current users of e-cigarettes, one third of current e-cigarettes users have never been tobacco smokers. A survey of American college students revealed that e-cigarette use is not motivated by the desire to stop tobacco smoking. Almost 300,000 school students reported having used e-cigarettes, they were mostly convinced no dangers of e-cigarette were proved.

Address for correspondence: Paweł Górski, Department of Pneumology and Allergy, Medical University of Lodz, ul. Kopcińskiego 22, 90-153 Łódź

e-mail: pawel.gorski@umed.lodz.pl

DOI: 10.5603/ARM.2017.0001

Received: 22.01.2017

Copyright (C) 2017 PTChP

ISSN 2451-4934 
Many doctors and the expert consensus recommmend the use e-cigarettes as a smoking cessation aid. However, surveys and observational studies have yielded conflicting results. Five studies found no association between e-smoking and quitting convencional cigarettes, and only one found documented reduction of the number of cigarettes smoked per day. An interesting Italian study on a comparison of the effectiveness of nicotine content of e-cigarettes and cigarettes that did not deliever nicotine showed no differences in reduction of the number of conventional cigarettes smoked per day during 1 year of the observation [4]. One study reported that switching from conventional to e-cigarettes in asthmatic patients may improve symptoms and lung function [5].

In this issue of „Advances in Respiratory Medicine” we can find interesting discussion pro/ contra in the context of neccessary statement of Polish experts [6,7]. One paper showed many influences of e-cigarettes on cells, lung function, lung development and diseases progress that should be considered. Moreover, some studies indicate that the use of e-cigarettes significantly increases the risk of a following tobacco smoking among young people. It might be explained by the fact of rapid absorption of nicotine from the lung in contrast to the agents absorbed from the gastrointestinal tract when gums are used for quitting tobacco smoking habit. In another presented study [8], one can find an observation that the intensity of e-smoking is larger than tobacco smoking among students of medicine in one of the largest medical school in Poland. It suggests a potential increase of tobacco smoking in the next years. In contrast, the author presented results a study on motivation, where an attempt to quit tobacco smoking was the most frequently reported factor. However, no convincing data on effectiveness of switching from tobacco to e-cigarettes exist. Many authors indicate a liability to nicotine-rich e-cigarettes and a future switch to conventional smoking habit.

NIH workshop in 2015 presented almost 50 research gaps that should be explained before the recommendation might be accepted [9]. It seems however, that doctors can use this method in the practice only as an aid of smoking cessation in some individuals. Special caution of switching should be recommended in pregnant women. Although some countries accepted e-cigarettes in pregnant smokers, others did not. There is also a need for establishing standard contents of nicotine and other potential harmful agents and a permanent monitoring of a quality of e-cigarettes on different markets.

We can conclude that it is too early to recommend the common use of e-cigarettes in a struggle against nicotine addiction, especially in young people. Health effects, in particular cancerogenic ones, have yet to be explored. Health systems should start controlling markets with respect to the quality of delivery systems and contents of nicotine and vaporized additives in available e-cigarettes. Many aspects still wait for explanation.

\section{Conflict of interest}

The author declares no conflict of interest.

\section{References:}

1. Brownson EG, Thompson CM, Goldsberry S, et al. Explosion Injuries from E-Cigarettes. N Engl J Med. 2016; 375(14): 1400-1402, doi: 10.1056/NEJMc1608478, indexed in Pubmed: 27705271.

2. McMillen RC, Gottlieb MA, Shaefer RM, et al. Trends in Electronic Cigarette Use Among U.S. Adults: Use is Increasing in Both Smokers and Nonsmokers. Nicotine Tob Res. 2015; 17(10): 1195-1202, doi: 10.1093/ntr/ntu213, indexed in Pubmed: 25381306.

3. Electronic Nicotine Delivery Systems. Pediatrics. 2015; 136(5): 1018-1026, doi: 10.1542/peds.2015-3222.

4. Caponnetto P, Campagna D, Cibella F, et al. EffiCiency and Safety of an eLectronic cigAreTte (ECLAT) as tobacco cigarettes substitute: a prospective 12-month randomized control design study. PLoS ONE. 2013; 8(6): e66317, doi: 10.1371/ journal.pone.0066317, indexed in Pubmed: 23826093.

5. Polosa R, Morjaria JB, Caponnetto P, et al. Persisting long term benefits of smoking abstinence and reduction in asthmatic smokers who have switched to electronic cigarettes. Discov Med. 2016; 21(114): 99-108, doi: 10.1016/i.jaci.2015.12.017, indexed in Pubmed: 27011045.

6. Zielonka TM. A debate: Can we recommend electronic cigarettes to our patients? Opinion 1. Adv Respir Med. 2017; 86: 35-39. doi: 10.5603/ARM.2017.0007.

7. Poznański M. A debate: Can we recommend electronic cigarettes to our patients? Opinion 2. Adv Respir Med. 2017; 86 40-45. 10.5603/ARM.2017.0008.

8. Brożek G, Jankowski M, Zejda J, Jarosińska A, Idzik A, Bańka P. E-smoking among students of medicine - frequency, pattern and motivations. Adv Respir Med. 2016; 85: 8-14. doi: 10.5603/ARM.2017.0003.

9. Walton KM, Abrams DB, Bailey WC, et al. NIH electronic cigarette workshop: developing a research agenda. Nicotine Tob Res. 2015; 17(2): 259-269, doi: 10.1093/ntr/ntu214, indexed in Pubmed: 25335949 . 